\title{
Effects of tranexamic acid on postoperative bleeding and related hematochemical variables in coronary surgery: Comparison between on-pump and off-pump techniques
}

\author{
Valter Casati, MD \\ Patrizia Della Valle, BS ${ }^{b}$ \\ Stefano Benussi, MD, PhD ${ }^{\mathrm{c}}$ \\ Annalisa Franco, $M D^{\mathrm{d}}$ \\ Chiara Gerli, MD ${ }^{\mathrm{d}}$ \\ Paolo Baili, $\mathrm{MS}^{\mathrm{e}}$ \\ Ottavio Alfieri, MD \\ Armando D'Angelo, $\mathrm{MD}^{\mathrm{b}}$
}

From the Division of Cardiovascular Anes-
thesia and Intensive Care, ${ }^{\text {a }}$ Policlinico di
Monza, Monza, Italy; the Coagulation Ser-
vice and Thrombosis Research Unit, ${ }^{\text {, the }}$
Department of Anesthesia, ${ }^{\text {c }}$ and the Divi-
sion of Cardiac Surgery, ${ }^{\text {d }}$ San Raffaele
Hospital, Milan, Italy; and the Epidemiol-
ogy Unit, ${ }^{\mathrm{e}}$ Istituto Nazionale per lo Studio e
la Cura dei Tumori, Milan, Italy.

Supported in part by a grant of the Italian Ministry of Health (contract ICS 160.3/ RF99.88).

Received for publication April 16, 2003; revisions requested Sept 30, 2003; accepted for publication Oct 7, 2003

Address for reprints: Valter Casati, MD, Division of Cardiovascular Anesthesia and Intensive Care, Policlinico di Monza, via Amati 111, Monza (20052), Italy (E-mail: valter.casati@policlinicodimonza.it).

J Thorac Cardiovasc Surg 2004;128:83-91 $0022-5223 / \$ 30.00$

Copyright (C) 2004 by The American Association for Thoracic Surgery

doi:10.1016/j.jtcvs.2003.10.034
Objectives: Bleeding and inflammation are major complications of extracorporeal circulation. Off-pump coronary artery bypass grafting may reduce the rate of complications, but it can only be applied in selected cases. Pilot studies have shown a potential benefit from the use of antifibrinolytic drugs, but efficacy in randomized double-blind studies evaluating off- and on-pump coronary artery bypass grafting has not been proved.

Methods: We enrolled 102 patients scheduled for on-pump $(\mathrm{n}=51)$ or off-pump (n $=51$ ) coronary artery bypass grafting. Patients were separately double-blind randomly assigned to treatment with tranexamic acid $(1 \mathrm{~g}$ as 20 -minute bolus before skin incision, followed by continuous infusion of $400 \mathrm{mg} / \mathrm{h}$, with $500 \mathrm{mg}$ added to priming in patients undergoing on-pump coronary artery bypass grafting) or placebo (saline solution of equivalent volume). Bleeding in the first 24 postoperative hours was the primary outcome. Requirement for allogeneic transfusions, thrombotic complications, outcomes, and monitoring of coagulation, fibrinolysis, and inflammation were also recorded.

Results: Tranexamic acid reduced total postoperative bleeding by $43 \%$ in patients undergoing on-pump coronary artery bypass grafting and by $27 \%$ in those undergoing off-pump coronary artery bypass grafting $(P<.0001)$, with $80 \%$ reduction in bleeding exceeding $600 \mathrm{~mL}(P<.001), 58 \%$ reduction in the requirement for all allogeneic transfusions $(P=.07)$, and no apparent effect on thrombotic complications or outcome. This was associated with a reduction in plasma D-dimer levels $(P$ $<.0001)$, to a greater degree in patients undergoing on-pump coronary artery bypass grafting $(P<.0001)$, and interleukin 6 levels $(P<.0001)$, to a greater degree in patients undergoing off-pump coronary artery bypass grafting $(P<.001)$.

Conclusions: By affecting fibrinolysis, tranexamic acid significantly reduces bleeding both in off- and on-pump coronary artery bypass grafting and may modulate inflammation in these surgical settings.

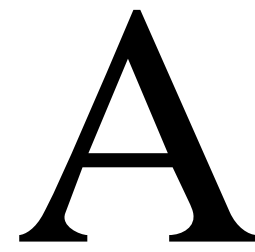

t present most cardiac surgery is performed with extracorporeal circulation. Excessive perioperative bleeding is most common among the well-known complications of cardiopulmonary bypass (CPB). ${ }^{1}$ Activation and consumption of platelets, activation of the intrinsic and extrinsic pathways of coagulation, and hyperfibrinolysis are all involved in the relatively frequent hemorrhagic diathesis seen in cardiac surgery. ${ }^{2-4}$ In addition, inflammation, albeit rarely leading 
to clinically relevant organ dysfunction, may affect the outcome of patients undergoing coronary artery bypass grafting $(\mathrm{CABG})^{5,6}$

Recently, CABG without $\mathrm{CPB}(\mathrm{OPCAB})$ was reintroduced in cardiac surgery, initially for selected patients and then for an increasing number of indications. ${ }^{7-9}$ Avoidance of CPB may reduce the prevalence of perioperative complications, particularly bleeding. However, there are large differences in terms of postoperative bleeding and allogeneic transfusions reported in published studies. ${ }^{10-12}$ At our institution, prophylactic infusion of tranexamic acid (TA), a synthetic antifibrinolytic drug with demonstrated hemostatic properties in cardiac surgery, ${ }^{13}$ has been previously studied in different types of patients undergoing cardiovascular surgery with $\mathrm{CPB},{ }^{14-17}$ and it was also found promising in a pilot study of patients undergoing OPCAB.$^{18}$ In this study we compared the hemostatic effects of TA in patients undergoing $\mathrm{CABG}$ with and without $\mathrm{CPB}$ and evaluated the effects of this drug on selected coagulation, fibrinolysis, and inflammation variables.

\section{Materials and Methods}

From January 3, 2001, to June 30, 2001, consecutive patients undergoing $\mathrm{OPCAB}$ and consecutive patients undergoing on-pump CABG (ONCAB) only if three or fewer distal anastomoses were to be performed were considered for the enrollment in the study. The criteria for the choice of surgery were predefined. Indications for $\mathrm{OPCAB}$ were as follows: single critical stenosis of the anterior descending coronary artery, without the possibility of a catheterbased intervention, restenosis after angioplasty or stent placement, or multivessel coronary disease in patients for whom CPB was contraindicated because of associated comorbid conditions (severe chronic obstructive pulmonary disease, cerebrovascular diseases, severe peripheral vascular disease). Exclusion criteria from the study were history of hematologic disease, chronic renal insufficiency (creatinine level $>2 \mathrm{mg} / \mathrm{dL}$ ), and liver disease (active chronic hepatitis or cirrhosis). Preoperative treatment with aspirin or subcutaneous low-molecular weight heparin was not a contraindication to inclusion in the study.

A total of 102 patients were enrolled: 51 patients constituted the OPCAB group, and 51 constituted the ONCAB group. By means of two separate computer-generated random number sequences, the patients assigned to OPCAB and ONCAB were double-blind randomly assigned to receive TA or placebo. TA was administered as a bolus injection of $1 \mathrm{~g}$ in 20 minutes before skin incision, followed by a continuous infusion of $400 \mathrm{mg} / \mathrm{h}$ until completion of surgery. Placebo consisted of an equivalent volume of saline solution. In ONCAB surgery, $500 \mathrm{mg}$ of the drug or an equivalent volume of saline solution was added to the priming of CPB. The staff in the operating room and the intensive care unit (ICU) were blinded regarding treatment: the correct procedure was ensured by means of coded syringes, prepared by a fellow in anesthesia not directly involved in the perioperative patient care and in the treatment of clinical data. The institutional review board approved the study, and written informed consent was obtained from each enrolled patient.
A standardized protocol of anesthesia was used for all patients. ${ }^{18,19}$ All the patients were operated on through a full median sternotomy. The left internal thoracic artery was harvested in each patient through conventional pleurotomy access; if required, the saphenous vein was also isolated.

\section{ONCAB Technique}

Before aortic cannulation, porcine mucous heparin $(3 \mathrm{mg} / \mathrm{kg}$ ) was administered to obtain during $\mathrm{CPB}$ an activated clotting time (ACT) longer than 480 seconds. The circuit for CPB included a centrifugal pump for nonpulsatile blood flow and a hollow-fiber membrane oxygenator. The priming solution of the circuit consisted of a balanced crystalloid-colloid solution (1350 mL Ringer lactate, $250 \mathrm{~mL} 18 \%$ mannitol, $150 \mathrm{~mL}$, plasma expander). Blood temperature was kept between $32^{\circ} \mathrm{C}$ and $35^{\circ} \mathrm{C}$. Myocardial protection during aortic crossclamping was achieved with blood cardioplegia according to the Buckberg method. At the end of CPB, the total dose of heparin administered was antagonized with protamine sulfate (1:1 ratio); if required, further doses of $50 \mathrm{mg}$ were administered to obtain an ACT value equal to or shorter than the baseline ACT. The remaining blood in the circuit and that aspired from the surgical field was concentrated with a cell separator and reinfused. During the postoperative period, no autotransfusion of mediastinal shed blood was performed.

\section{OPCAB Technique}

After the opening of the pericardium, the stabilizing system (Medtronic-Utrecht Octopus System; Medtronic Inc, Minneapolis, Minn) was positioned in the sternal wound. A heparin dose of 1 $\mathrm{mg} / \mathrm{kg}$ was administered, and an ACT longer than 250 seconds was maintained until the anastomoses were performed with supplementary doses of $50 \mathrm{mg}$. No drugs were administered to diminish heart frequency. Vessel occlusion was achieved, proximally and distally, with a 4-0 polytetrafluoroethylene suture passed through a silicone tube to avoid the direct contact between the suture and the wall of the coronary artery and tightened by tourniquets. After completion of all anastomoses, the total dose of heparin administered was antagonized with protamine sulfate (1:1 ratio); if required, further doses of $50 \mathrm{mg}$ were administered to obtain an ACT value equal to or shorter than baseline ACT. Only in cases of significant intraoperative bleeding was the shed blood concentrated in a cell separator and reinfused. No postoperative autotransfusion of mediastinal shed blood was performed. In the absence of perioperative bleeding complications patients received acetylsalicylic acid (orally) or lysine-acetylsalicylate (intravenously), starting on the evening of the first postoperative day.

\section{Blood Sampling and Processing}

Samples for hematochemical evaluation were obtained and analyzed as previously reported elsewhere. ${ }^{19}$ Briefly, sequential venous samples were obtained in all cases through the heparinized distal line of the central venous catheter and collected in siliconized Vacutainer tubes (Becton Dickinson, Plymouth, UK) at the following times: after the induction of anesthesia (time 1), 10 minutes after patient arrival in the ICU (time 2), and 24 hours after the operation (time 3). All samples were obtained with a twosyringe technique with minimal stasis: $10 \mathrm{~mL}$ of blood was aspired in the first syringe and discarded, and another $10 \mathrm{~mL}$ was then 
obtained with the second syringe for hematochemical evaluation. Within 1 hour from blood collection, platelet-poor plasma was obtained by centrifugation for 20 minutes at $2000 \mathrm{~g}$ at room temperature. Prothrombin time (PT) and activated partial thromboplastin time (APTT) were measured in fresh plasma samples. Aliquots of platelet-poor plasma $(0.5 \mathrm{~mL})$ were snap-frozen and stored at $-80^{\circ} \mathrm{C}$ until assay.

\section{Assay Methods}

All determinations of hemostatic variables were carried out with a fully automated coagulometer (STA Diagnostica; Stago, Asnier sur Seine, France). Reagents for APTT (STA APTT Kaolin), fibrinogen (STA Fibrinogen), D-dimer (STA Liatest D-DI), antithrombin III (amidolytic activity, STA Antithrombin III), and $\alpha_{2}$-antiplasmin (amidolytic activity, STA Antiplasmin) determinations were obtained from Roche Diagnostic (Mannheim, Germany). PT was measured with Hemoliance Recombiplastin IL (Instrumentation Laboratory, Lexington Mass), and plasminogen levels (amidolytic activity) were measured with the Coamatic kit (substrate S-2403; Chromogenix AB, Mölndal, Sweden). APTT and PT results were expressed as ratios, with the APTT and PT values measured in normal pooled plasma obtained from 40 healthy volunteers as denominators. The same normal pooled plasma, arbitrarily given a value of $100 \%$, was used to construct calibration curves for all the amidolytic assays.

Plasma immunoglobulin $\mathrm{G}$ (IgG) levels were measured by immunonephelometry (Tina-Quant IgG Kit; Boehringer Mannheim, Mannheim, Germany) in a Modular Hitachi 917 (Roche Diagnostic). Interleukin (IL) 6 was measured in citrated plasma by a commercially available enzyme-linked immunosorbent assay kit (Amersham Pharmacia Biotech UK Limited, Buckinghamshire, UK).

\section{Criteria for Allogeneic Transfusion and Surgical Reexploration}

Patients were transfused only in the presence of signs or symptoms of hypovolemia (hypotension or tachycardia) or diffuse bleeding. Perioperative criteria for allogeneic transfusions were standardized: in both groups packed red blood cells were transfused if the hemoglobin value was less than $8 \mathrm{~g} / \mathrm{dL}$ or the hematocrit was less than $24 \%$. Fresh-frozen plasma was infused if the PT value after protamine administration was at least 1.5 times the baseline, and platelet concentrates were transfused with platelet counts of $50,000 / \mathrm{mm}^{3}$ or less.

Blood loss was recorded during the first 24 hours, and excessive bleeding was defined as a blood loss greater than $600 \mathrm{~mL}$ in 24 hours. Chest drains were removed when bleeding was less than $100 \mathrm{~mL}$ in the preceding 4 hours. Surgical reexploration occurred when bleeding in the first 2 hours was greater than $300 \mathrm{~mL} / \mathrm{h}$, or when it was greater than $200 \mathrm{~mL} / \mathrm{h}$ for 4 consecutive hours, with normal coagulation variables.

\section{Secondary Outcomes}

During the first 24 postoperative hours, possible thrombotic complications as consequence of antifibrinolytic therapy were recorded. These were myocardial infarction (new Q waves at electrocardiography, creatine kinase MB isoenzyme ratio greater than $10 \%$, and troponin I $>0.1 \mathrm{ng} / \mathrm{dL}$ ), acute renal insufficiency (cre- atinine value twice the baseline or need for dialysis), major neurologic dysfunction (transient ischemic attack or stroke), deep venous thrombosis, and pulmonary embolism.

\section{Statistical Methods}

Considering as primary outcome the effects of TA on postoperative bleeding, the trial was designed to detect a difference of 200 $\mathrm{mL}$ in postoperative bleeding (SD $250 \mathrm{~mL}$ ) between the groups undergoing the same surgical approach. This design was based on data emerging from a previous study. ${ }^{14}$ To achieve significance, 25 patients per group were required, with a 1-tailed $\alpha$ error of .05 and $80 \%$ power. Analysis was conducted on an intent-to-treat basis.

Normality of the distribution of continuous variables was evaluated with the Kolmogorov-Smirnov test. Data are reported as mean $\pm \mathrm{SD}$ or median with interquartile range (25-75th percentile). Comparisons in continuous variables between patients randomly assigned to treatment in the two surgical groups were performed by analysis of variance after log transformation of nonnormally distributed variables. The $\chi^{2}$ test, the Fisher exact test, or Mantel-Haenszel odds ratios (adjusted for the surgical techniques) were used for comparisons of discrete variables.

The changes in hematochemical variables were evaluated by analysis of variance for repeated measures after log transformation of nonnormally distributed variables, including treatment and surgical technique as factors and preoperative values as covariate. Analysis was conducted on both unadjusted data and data adjusted for hemodilution according to the following formulas: $[\mathrm{IgG}]_{\text {initial }}$ - $[\mathrm{IgG}]_{\text {timepoint }} /[\mathrm{IgG}]_{\text {initial }}$ for hematochemical variables and Hematocrit $_{\text {initial }}-$ Hematocrit $_{\text {timepoint }} / \mathrm{Hematocrit}_{\text {initial }}$ for platelet counts. IgG levels were chosen as an indicator of hemodilution because they are not affected by surgery and are not involved in metabolic pathways altered early by trauma. Bonferroni correction was applied for post hoc comparisons.

\section{Results}

All patients completed the study. Two patients scheduled for OPCAB ( 1 in each treatment group) required conversion to ONCAB because of hemodynamic instability during the maneuvers of exposition of coronary vessels, but these cases were analyzed on an intent-to-treat basis and included in the OPCAB group.

Baseline characteristics and operative data are shown in Tables 1 and 2. There were no significant differences for patients assigned to TA or placebo within each surgical group. Patients undergoing OPCAB had lower left ventricular ejection fraction $(P=.004)$ and higher Higgins score ${ }^{20}$ $(P=.0004)$ than did those undergoing ONCAB (Table 1). Surgical time was significantly longer for ONCAB than for OPCAB $(P=.001)$, and higher doses of heparin and protamine were used in ONCAB $(P<.0001)$.

The extent of postoperative bleeding and the requirement for allogeneic transfusions are shown in Table 3. As expected, blood losses were higher in patients undergoing ONCAB than in those undergoing OPCAB $(P=.007)$, but TA reduced early bleeding and 24-hour bleeding in both groups $(P<.0001)$. There was a trend toward a greater 
TABLE 1. Demographic and baseline characteristics of patients undergoing CABG

\begin{tabular}{|c|c|c|c|c|c|}
\hline \multirow[b]{2}{*}{ Variable } & \multicolumn{2}{|c|}{ ОРСАВ } & \multicolumn{2}{|c|}{ ONCAB } & \multirow[b]{2}{*}{$P$ value* } \\
\hline & $\begin{array}{l}\text { Placebo } \\
(\mathrm{n}=25)\end{array}$ & $\begin{array}{c}\text { TA } \\
(n=26)\end{array}$ & $\begin{array}{l}\text { Placebo } \\
\text { (n = 25) }\end{array}$ & $\begin{array}{c}\text { TA } \\
(n=26)\end{array}$ & \\
\hline Age $(y$, mean $\pm S D)$ & $61 \pm 11$ & $64 \pm 12$ & $60 \pm 9$ & $64 \pm 9$ & .41 \\
\hline Male sex (No.) & $21(84 \%)$ & $20(76.9 \%)$ & $21(84 \%)$ & $24(92.3 \%)$ & .85 \\
\hline Height $(\mathrm{cm}$, mean $\pm S D)$ & $169 \pm 7$ & $168 \pm 9$ & $171 \pm 6$ & $172 \pm 6$ & .18 \\
\hline Weight $(\mathrm{kg}$, mean $\pm \mathrm{SD})$ & $73 \pm 10$ & $71 \pm 12$ & $77 \pm 9$ & $77 \pm 12$ & .08 \\
\hline $\begin{array}{l}\text { Baseline left ventricular ejection } \\
\text { fraction }(\% \text {, mean } \pm \text { SD) }\end{array}$ & $46 \pm 13$ & $43 \pm 14$ & $52 \pm 11$ & $50 \pm 11$ & $.023 \dagger$ \\
\hline $\begin{array}{l}\text { Previous acute myocardial } \\
\text { infarction (No.) }\end{array}$ & $17(68 \%)$ & $19(73.1 \%)$ & $13(52 \%)$ & $11(42.3 \%)$ & .9 \\
\hline \multicolumn{6}{|l|}{ Coexisting illness (No.) } \\
\hline Hypertension & $7(28 \%)$ & $4(15.4 \%)$ & $8(30.8 \%)$ & $6(23 \%)$ & .55 \\
\hline Diabetes & $5(20 \%)$ & $5(19.2 \%)$ & $6(24 \%)$ & $4(15.4 \%)$ & .89 \\
\hline Peripheral vascular disease & $3(12 \%)$ & $1(3.8 \%)$ & $2(8 \%)$ & $3(11.5 \%)$ & .70 \\
\hline $\begin{array}{l}\text { Chronic obstructive pulmonary } \\
\text { disease }\end{array}$ & $2(8 \%)$ & $2(7.7 \%)$ & $4(16 \%)$ & $2(7.7 \%)$ & .71 \\
\hline $\begin{array}{l}\text { Higgins score (median and } \\
\text { interquartile range) }\end{array}$ & $3(2-6)$ & $3(2-6)$ & $1(0-2)$ & $2(1-3)$ & $.0012 \dagger$ \\
\hline Preoperative aspirin, $\mathrm{n}(\%)$ & $7(28 \%)$ & $6(23.1 \%)$ & $7(28 \%)$ & $6(23.1 \%)$ & .95 \\
\hline $\begin{array}{l}\text { Preoperative low-molecular } \\
\text { weight heparin (No.) }\end{array}$ & $3(12 \%)$ & $4(15.4 \%)$ & $5(20 \%)$ & $4(15.4 \%)$ & .35 \\
\hline
\end{tabular}

${ }^{*} P$ value for comparison of four groups.

$\dagger P<.0001$ for OPCAB versus ONCAB.

TABLE 2. Operative data

\begin{tabular}{|c|c|c|c|c|c|}
\hline \multirow[b]{2}{*}{ Variable } & \multicolumn{2}{|c|}{ OPCAB } & \multicolumn{2}{|c|}{ ONCAB } & \multirow[b]{2}{*}{$P$ value* } \\
\hline & $\begin{array}{l}\text { Placebo } \\
\text { (n = 25) }\end{array}$ & $\begin{array}{c}\text { TA } \\
(n=26)\end{array}$ & $\begin{array}{l}\text { Placebo } \\
\text { (n = 25) }\end{array}$ & $\begin{array}{c}\text { TA } \\
(n=26)\end{array}$ & \\
\hline Resternotomy (No.) & $2(8 \%)$ & $3(11.5 \%)$ & $3(12 \%)$ & $4(15.4 \%)$ & .88 \\
\hline CPB time (min) & $0(0-0)$ & $0(0-0)$ & $90(62-116)$ & $83(60-96)$ & $<.0001 \dagger$ \\
\hline $\begin{array}{l}\text { Aortic crossclamp time } \\
\text { (min) }\end{array}$ & $0(0-0)$ & $0(0-0)$ & $65(44-88)$ & $59(43-85)$ & $<.0001 \dagger$ \\
\hline Surgical time (min) & $165(122-193)$ & $178(124-243)$ & $234(185-275)$ & $227(183-247)$ & $.001 \dagger$ \\
\hline Distal anastomoses & $2(1-3)$ & $2(1-3)$ & $2(2-3)$ & $2(2-3)$ & .35 \\
\hline Total heparin dose $(\mathrm{mg})$ & $80(70-100)$ & $80(71-98)$ & $240(220-270)$ & $240(210-258)$ & $<.0001 \dagger$ \\
\hline $\begin{array}{l}\text { Total protamine dose } \\
(\mathrm{mg})\end{array}$ & $80(70-100)$ & $80(71-100)$ & $250(240-300)$ & $250(220-300)$ & $<.0001 \dagger$ \\
\hline
\end{tabular}

Except as indicated, all values are median and interquartile range.

${ }^{*} P$ value for comparison of four groups.

$\dagger P<.0001$ for OPCAB versus ONCAB.

reduction of early bleeding in patients undergoing $\mathrm{OPCAB}$ (52\% vs $22 \%, P=.052$ ), but total postoperative bleeding was reduced to a similar extent in both groups $(43 \%$ vs $27 \%$, $P=.9)$. In addition, relative to placebo-treated patients, patients who received TA had a much lower probability of bleeding in excess of $600 \mathrm{~mL}$ in the first 24 postoperative hours (Mantel-Haenszel odds ratio 0.18, 95\% confidence interval 0.08-0.43). The rate of bleeding was not influenced by preoperative low-molecular weight heparin treatment, irrespective of the type of surgery and TA treatment (data not shown). Among patients undergoing ONCAB there were 1 reexploration for bleeding in the TA group and 3 in the placebo group (odds ratio $0.21, P=.38$ ). A surgical source of bleeding was identified at reexploration in 2 patients (1 in TA group and 1 in placebo group). Consistent with these findings, the number of patients requiring allogeneic transfusions was lower in the TA group, although this difference did not reach statistical significance. The amount of packed red blood cell units transfused, which was significantly higher in patients undergoing ONCAB than in those undergoing OPCAB $(P<.0001)$, and the numbers of fresh-frozen plasma and platelet concentrate units trans- 
TABLE 3. Postoperative bleeding and perioperative allogeneic transfusions

\begin{tabular}{|c|c|c|c|c|c|}
\hline \multirow[b]{2}{*}{ Variable } & \multicolumn{2}{|c|}{ OPCAB } & \multicolumn{2}{|c|}{ ONCAB } & \multirow[b]{2}{*}{$P$ value* } \\
\hline & $\begin{array}{l}\text { Placebo } \\
\text { (n = 25) }\end{array}$ & $\begin{array}{c}\text { TA } \\
(n=26)\end{array}$ & $\begin{array}{l}\text { Placebo } \\
\text { (n = 25) }\end{array}$ & $\begin{array}{c}\text { TA } \\
(n=26)\end{array}$ & \\
\hline $\begin{array}{l}\text { Bleeding in first } 4 \mathrm{~h}(\mathrm{~mL} \text {, median and } \\
\text { interquartile range) }\end{array}$ & $311(255-450)$ & $150(100-190)$ & $352(310-550)$ & $275(223-338)$ & $<.0001 \dagger$ \\
\hline $\begin{array}{l}\text { Total bleeding in } 24 \mathrm{~h}(\mathrm{~mL} \text {, median and } \\
\text { interquartile range) }\end{array}$ & $654(510-820)$ & $375(356-550)$ & $754(550-1200)$ & $552(422-704)$ & $<.0001 \ddagger$ \\
\hline Excessive bleeding (No.) & $15(60 \%)$ & $3(11.5 \%)$ & $17(68 \%)$ & $10(38.5 \%)$ & $<.0005 \S$ \\
\hline Reexploration for bleeding (No.) & 0 & 0 & $3(12 \%)$ & $1(3.9 \%)$ & .57 \\
\hline $\begin{array}{l}\text { Transfusions with packed red blood cells } \\
\text { (No.) }\end{array}$ & $4(16 \%)$ & $3(11.5 \%)$ & $9(36 \%)$ & $6(23.1 \%)$ & .41 \\
\hline Total packed red blood cells (units) & 11 & 6 & 32 & 23 & $<.0001 \dagger$ \\
\hline Transfusions with fresh-frozen plasma (No.) & $2(8 \%)$ & $0(0 \%)$ & $4(16 \%)$ & $1(3.9 \%)$ & .13 \\
\hline Total fresh-frozen plasma (units) & 10 & 0 & 24 & 18 & .88 \\
\hline Transfusions with platelet concentrate (No.) & $0(0 \%)$ & $0(0 \%)$ & $2(8 \%)$ & $1(3.9 \%)$ & .28 \\
\hline Total platelet concentrate (units) & 0 & 0 & 14 & 7 & .99 \\
\hline
\end{tabular}

Bleeding was defined excessive for losses greater than $600 \mathrm{~mL}$ in the first 24 postoperative hours.

${ }^{*} P$ value for comparison of four groups.

$\mathrm{t} P<.0001$ for $0 \mathrm{PCAB}$ versus $0 \mathrm{NCAB}, P<.0001$ for TA versus placebo.

$\ddagger P=.007$ for OPCAB versus ONCAB, $P<.0001$ for TA versus placebo.

$\S P<.0001$ for TA versus placebo.

fused were reduced by $40 \%, 80 \%$, and $50 \%$ in the TA group, with a total number of 54 units in the TA group versus 91 in the placebo group $(P=.07)$.

Intubation time (median 10 hours, interquartile range 7-13 hours), ICU stay (median 1 day, interquartile range 1-2 days), hospital stay (median 8 days, interquartile range 6-10 days), and the percentages of patients requiring major inotropic therapy $(9 \%)$ or mechanical ventilation for longer than 48 hours $(5 \%)$ or with postoperative atrial fibrillation (24\%), myocardial infarction (4\%), or renal insufficiency $(2.5 \%)$ were similar in the four groups of patients (in all cases $P>.3$ ). No patients had stroke or clinical pulmonary embolism. Two patients died in the OPCAB group (1 in each treatment group), and 1 died in the CABG placebo group $(P>.5)$.

The changes in hematochemical variables (unadjusted for hemodilution) are reported in Table 4. Baseline levels of the variables considered were similar in all patient groups $(P>.2)$. With the exception of PT and APTT values (not shown), all variables showed significant variations with time. Changes in hemoglobin, hematocrit, fibrinogen, antithrombin III, and $\alpha_{2}$-antiplasmin were influenced only by the surgical technique. With the exception of $\alpha_{2}$-antiplasmin, all these values decreased after the operation $(P<$ .0001 ), but they decreased to a greater extent in patients undergoing ONCAB than in those undergoing OPCAB $(P$ $<.01)$ and were still lower in patients who underwent ONCAB 24 hours after the operation $(P<.0001)$. Platelet counts decreased to a significant extent after the operation only in patients undergoing ONCAB $(P<.0001)$, and they were still lower 24 hours after the operation in these patients
$(P<.0001)$. Both treatment and type of surgery influenced the changes in the other variables examined. Plasminogen levels decreased significantly in all patient groups after the operation $(P<.0001)$, but they decreased to a greater extent in those treated with TA $(P<.0001)$ and in those undergoing $\mathrm{ONCAB}(P<.0001)$, and they were still lower in these patients 24 hours after the operation $(P<.001)$.

D-dimer levels increased after the operation only in patients receiving placebo $(P<.0001)$, and to a greater extent in those undergoing ONCAB $(P<.0001)$. The day after the operation, D-dimer levels were still lower in patients treated with TA $(P<.0001)$, irrespective of the surgical technique. IgG levels decreased in all patients after the operation $(P<.02)$, and they did so to a greater extent in patients undergoing $\mathrm{ONCAB}(P<.0001)$ and in those receiving placebo $(P<.005)$. The day after the operation, IgG levels were still lower in patients undergoing ONCAB $(P<.0001)$ and in patients treated with placebo $(P=.025)$. IL-6 levels increased in all patients after the operation, but they decreased to a greater extent in patients undergoing ONCAB $(P<.0001)$ and to a lesser extent in patients receiving TA $(P<.0001)$. In addition, modulation of IL-6 levels by TA was greater in patients undergoing OPCAB $(P$ $<$.001). Twenty-four hours after the operation, IL-6 levels were still lower in patients undergoing OPCAB and in those treated with TA $(P=.001)$.

After correction for hemodilution, antithrombin III and fibrinogen levels decreased to similar extents in patients undergoing $\mathrm{OPCAB}$ and $\mathrm{ONCAB}$, irrespective of treatment (data not shown). Changes in selected hemostatic variables adjusted for hemodilution are shown in Figure 1. Irrespec- 
TABLE 4. Postoperative changes in laboratory variables

\begin{tabular}{|c|c|c|c|c|c|c|c|c|c|c|c|}
\hline & \multirow[b]{2}{*}{ Group } & \multicolumn{3}{|c|}{ OPCAB } & \multicolumn{3}{|c|}{ ONCAB } & \multicolumn{4}{|c|}{ Analysis of variance for repeated measures } \\
\hline & & Time 1 & Time 2 & Time 3 & Time 1 & Time 2 & Time 3 & Time & $\begin{array}{l}\text { Time } \times \\
\text { treatment }\end{array}$ & $\begin{array}{l}\text { Time } \times \\
\text { surgery }\end{array}$ & $\begin{array}{c}\text { Time } \times \\
\text { treatment } \\
\times \text { surgery }\end{array}$ \\
\hline Hemo & Placebo & $14.6 \pm 1.6$ & $12.6 \pm 1.3$ & $11.8 \pm 1.5$ & $14.6 \pm 1.1$ & $11.5 \pm 1.4$ & $11.0 \pm 1.4$ & $<.0001$ & .21 & .025 & .09 \\
\hline$(g / d L)$ & TA & $13.5 \pm 1.8$ & $11.3 \pm 1.4$ & $11.5 \pm 1.5$ & $14.2 \pm 0.9$ & $11.6 \pm 1.4$ & $11.4 \pm 1.3$ & & & & \\
\hline Hematocrit & $\begin{array}{l}\text { Placebo } \\
\text { TA }\end{array}$ & $\begin{array}{l}43.4 \pm 3.8 \\
40.2 \pm 4.8\end{array}$ & $\begin{array}{l}37.8 \pm 3.4 \\
34.2 \pm 4.2\end{array}$ & $\begin{array}{l}35.4 \pm 4.3 \\
34.7 \pm 3.7\end{array}$ & $\begin{array}{l}43.0 \pm 3 \\
42.2 \pm 2.8\end{array}$ & $\begin{array}{l}34.6 \pm 4.1 \\
34.9 \pm 4.2\end{array}$ & $\begin{array}{l}33.7 \pm 5.5 \\
34.4 \pm 4.1\end{array}$ & $<.001$ & .41 & .035 & .12 \\
\hline $\begin{array}{l}\text { Platelets }\left(10^{3}\right. \\
\left.\text { cells } / \mathrm{mm}^{3}\right)\end{array}$ & $\begin{array}{l}\text { Placebo } \\
\text { TA }\end{array}$ & $\begin{array}{l}223 \pm 86 \\
217 \pm 100\end{array}$ & $\begin{array}{l}193 \pm 82 \\
186 \pm 89\end{array}$ & $\begin{array}{l}188 \pm 83 \\
188 \pm 65\end{array}$ & $\begin{array}{l}201 \pm 54 \\
202 \pm 58\end{array}$ & $\begin{array}{l}119 \pm 33 \\
138 \pm 36\end{array}$ & $\begin{array}{l}128 \pm 44 \\
153 \pm 72\end{array}$ & .34 & .19 & $<.0001$ & .27 \\
\hline $\begin{array}{c}\text { Fibrinogen } \\
\text { (mg/dL) }\end{array}$ & $\begin{array}{l}\text { Placebo } \\
\text { TA }\end{array}$ & $\begin{array}{l}363 \pm 79 \\
328 \pm 87\end{array}$ & $\begin{array}{l}293 \pm 67 \\
278 \pm 92\end{array}$ & $\begin{array}{l}425 \pm 81 \\
378 \pm 98\end{array}$ & $\begin{array}{l}353 \pm 81 \\
337 \pm 80\end{array}$ & $\begin{array}{l}231 \pm 69 \\
231 \pm 58\end{array}$ & $\begin{array}{l}360 \pm 83 \\
385 \pm 91\end{array}$ & $<.0001$ & .60 & $<.0001$ & .09 \\
\hline $\begin{array}{l}\text { D-dimer (mg/L, } \\
\text { median and }\end{array}$ & Placebo & $\begin{array}{c}0.74 \\
(0.44-1.73)\end{array}$ & $\begin{array}{c}0.84 \\
(0.50-1.15)\end{array}$ & $\begin{array}{c}1.35 \\
(0.73-2.36)\end{array}$ & $\begin{array}{c}0.61 \\
(0.48-1.02)\end{array}$ & $\begin{array}{c}2.31 \\
(1.76-3.72)\end{array}$ & $\begin{array}{c}1.18 \\
(0.72-1.58)\end{array}$ & .20 & $<.0001$ & $<.0001$ & $<.001$ \\
\hline $\begin{array}{l}\text { interquartile } \\
\text { range) }\end{array}$ & $\mathrm{TA}$ & $\begin{array}{c}0.46 \\
(0.34-0.89)\end{array}$ & $\begin{array}{c}0.41 \\
(0.22-0.68)\end{array}$ & $\begin{array}{c}0.51 \\
(0.29-1.27)\end{array}$ & $\begin{array}{c}0.66 \\
(0.35-0.88)\end{array}$ & $\begin{array}{c}0.51 \\
(0.31-0.92)\end{array}$ & $\begin{array}{c}0.65 \\
(0.49-0.92)\end{array}$ & & & & \\
\hline $\begin{array}{l}\text { Antithrombin III } \\
(\%)\end{array}$ & $\begin{array}{l}\text { Placebo } \\
\text { TA }\end{array}$ & $\begin{array}{l}83 \pm 16 \\
78 \pm 12\end{array}$ & $\begin{array}{l}67 \pm 12 \\
64 \pm 13\end{array}$ & $\begin{array}{l}69 \pm 11 \\
68 \pm 9\end{array}$ & $\begin{array}{l}85 \pm 8 \\
82 \pm 13\end{array}$ & $\begin{array}{l}58 \pm 12 \\
61 \pm 10\end{array}$ & $\begin{array}{l}62 \pm 12 \\
66 \pm 12\end{array}$ & .001 & .09 & $<.001$ & .59 \\
\hline $\begin{array}{l}\text { Plasminogen } \\
(\%)\end{array}$ & $\begin{array}{l}\text { Placebo } \\
\text { TA }\end{array}$ & $\begin{array}{l}99 \pm 17 \\
93 \pm 17\end{array}$ & $\begin{array}{l}83 \pm 17 \\
69 \pm 23\end{array}$ & $\begin{array}{l}79 \pm 20 \\
70 \pm 16\end{array}$ & $\begin{array}{r}100 \pm 18 \\
95 \pm 16\end{array}$ & $\begin{array}{l}73 \pm 13 \\
58 \pm 12\end{array}$ & $\begin{array}{l}72 \pm 20 \\
61 \pm 15\end{array}$ & .12 & .001 & $<.001$ & .94 \\
\hline $\begin{array}{l}\alpha_{2} \text {-antiplasmin } \\
(\%)\end{array}$ & $\begin{array}{l}\text { Placebo } \\
\text { TA }\end{array}$ & $\begin{array}{l}89 \pm 10 \\
82 \pm 14\end{array}$ & $\begin{array}{l}71 \pm 12 \\
69 \pm 16\end{array}$ & $\begin{array}{l}86 \pm 10 \\
78 \pm 15\end{array}$ & $\begin{array}{l}91 \pm 20 \\
88 \pm 15\end{array}$ & $\begin{array}{l}63 \pm 15 \\
61 \pm 14\end{array}$ & $\begin{array}{l}77 \pm 19 \\
82 \pm 15\end{array}$ & .0001 & .95 & .002 & .07 \\
\hline $\begin{array}{l}\text { IL-6 }(\mathrm{pg} / \mathrm{mL} \text {, } \\
\text { median and } \\
\text { interquartile } \\
\text { range) }\end{array}$ & Placebo & $\begin{array}{c}0.8 \\
(0-2.2) \\
2.3 \\
(0.8-5.6)\end{array}$ & $\begin{array}{c}44 \\
(22-87) \\
23 \\
(10-61)\end{array}$ & $\begin{array}{c}73 \\
(36-134) \\
76 \\
(50-92)\end{array}$ & $\begin{array}{c}1.7 \\
(0-8.1) \\
0.5 \\
(0-5.7)\end{array}$ & $\begin{array}{c}126 \\
(68-229) \\
103 \\
(45-165)\end{array}$ & $\begin{array}{c}54 \\
(30-81) \\
68 \\
(34-89)\end{array}$ & $<.0001$ & .045 & $<.0001$ & .49 \\
\hline $\lg G(g / L)$ & $\begin{array}{l}\text { Placebo } \\
\text { TA }\end{array}$ & $\begin{array}{l}8.0 \pm 2.1 \\
7.5 \pm 1.7\end{array}$ & $\begin{array}{l}6.4 \pm 1.3 \\
6.6 \pm 1.9\end{array}$ & $\begin{array}{l}6.3 \pm 1.4 \\
6.5 \pm 1.6\end{array}$ & $\begin{array}{l}7.7 \pm 1.4 \\
8.1 \pm 2.1\end{array}$ & $\begin{array}{l}5.5 \pm 1.8 \\
5.9 \pm 1.5\end{array}$ & $\begin{array}{l}4.9 \pm 1.0 \\
5.8 \pm 1.6\end{array}$ & .02 & .003 & $<.0001$ & .271 \\
\hline
\end{tabular}

All values are mean \pm SD unless otherwise specified. Time 1, After induction of anesthesia; Time 2, 10 minutes after arrival in ICU; Time 3, 24 hours after surgery; $T A$, tranexamic acid.

tive of treatment, platelet counts decreased after the operation only in patients undergoing $\mathrm{ONCAB}(P<.0001)$, whereas, irrespective of type of surgery, plasminogen and $\alpha_{2}$-antiplasmin levels were lower after the operation in patients receiving TA $(P<.0001)$. In addition, $\alpha_{2}$-antiplasmin levels were higher in patients undergoing ONCAB than in those undergoing $\mathrm{OPCAB}(P=.037)$. D-dimer levels were higher after the operation in patients receiving placebo $(P<.001)$ and in those undergoing $\mathrm{ONCAB}(P=.002)$. Fibrinogen and $\alpha_{2}$-antiplasmin levels 24 hours after the operation (adjusted for hemodilution) were strongly associated with IL-6 levels measured at the end of the procedure (unadjusted for hemodilution, $P<.0001$ ). Mirroring IL-6 levels, both variables were higher in patients undergoing ONCAB $(P=.0001)$ and in those treated with placebo $(P$ $=.0001)$, with the modulating effect of TA more pronounced in patients undergoing $\mathrm{OPCAB}(P=.01$, Figure 2).

\section{Discussion}

Perioperative hemorrhagic disorders remain the most common complication in cardiac surgery performed with $\mathrm{CPB}$, mainly because of activation and consumption of platelets and hyperfibrinolysis. ${ }^{3-5}$ OPCAB has been recently reintroduced into surgical practice, with the potential advantage of reducing the hemostatic alterations resulting from CPB. However, these alterations are probably only partially dependent on contact activation during $\mathrm{CPB}$, because activation of the extrinsic pathway of coagulation has been reported a major trigger for thrombin formation in cardiac surgery. ${ }^{5,21}$ Thus although a number of studies have documented significant reduction in perioperative bleeding and in the need for allogeneic transfusions with OPCAB, this improvement has occurred to a variable extent. Ascione and coworkers ${ }^{11}$ reported significant reduction in postoperative blood loss, transfusion requirement, and transfusion-related costs for patients undergoing $\mathrm{OPCAB}$, but Van Dijk and coworkers ${ }^{12}$ reported a difference of only $90 \mathrm{~mL}$ in terms of bleeding between patients undergoing OPCAB and ONCAB, without any difference in the percentage of patients transfused.

One of the most common blood-sparing maneuvers in cardiac surgery is the use of drugs with antifibrinolytic properties, such as aprotinin, $\epsilon$-aminocaproic acid, and TA. ${ }^{13}$ At our institution TA is widely used in patients undergoing surgery with $\mathrm{CPB} .{ }^{14-17}$ In a previously published pilot study, we tested the effects of TA in patients 

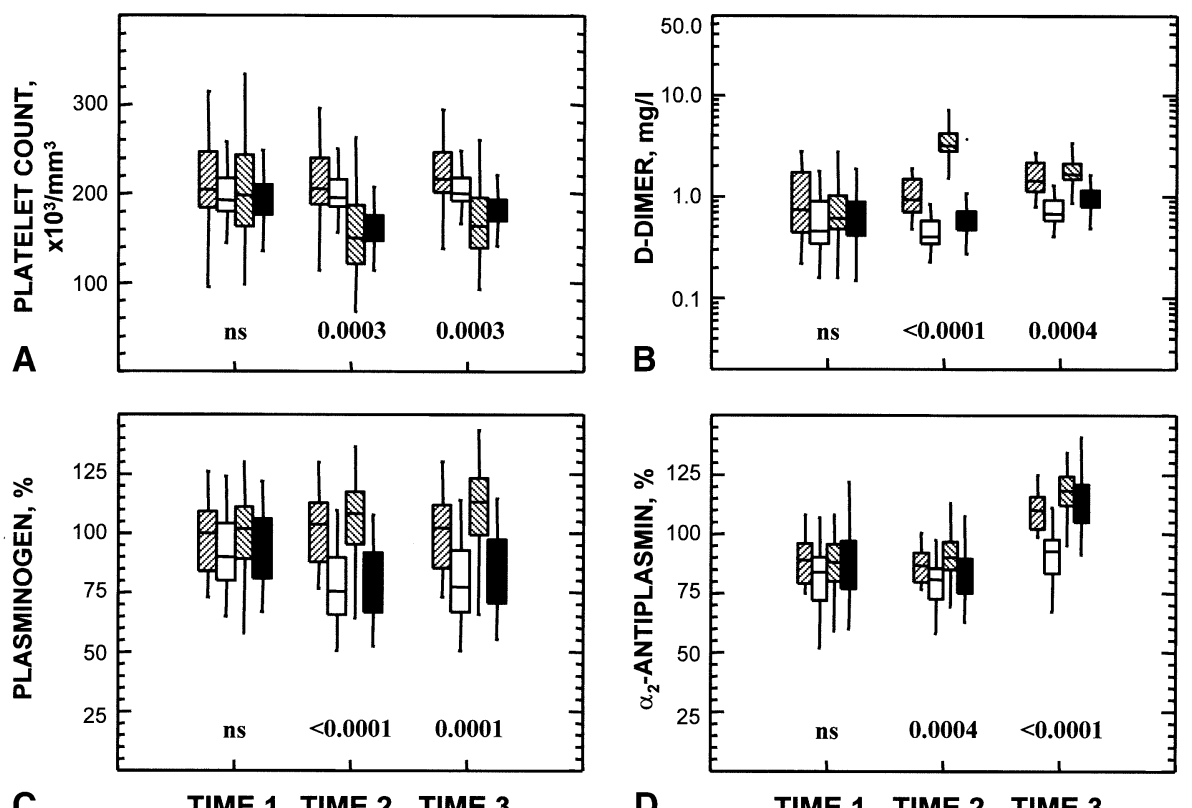

D

TIME 1 TIME 2 TIME 3

Figure 1. Changes (adjusted for hemodilution) in platelet counts (A), D-dimer levels (B), plasminogen levels (C), and $\alpha_{2}$-antiplasmin levels (D) in patients undergoing OPCAB or ONCAB and receiving placebo or TA at time 1 (after induction of anesthesia), time 2 (10 minutes after arrival in ICU), and time 3 (24 hours after end of operation). Box plots with medians (horizontal lines), interquartile ranges (boxes), and 95\% confidence intervals (vertical lines) are shown. Diagonal fills slanting downward from right represent $\mathrm{OPCAB}$ and placebo; white fills represent $\mathrm{OPCAB}$ and TA; diagonal fills slanting downward from right represent ONCAB and placebo; black fills represent ONCABG and TA. $P$ values refer to analysis of variance for repeated measures (see text for explanation). ns, Not significant.

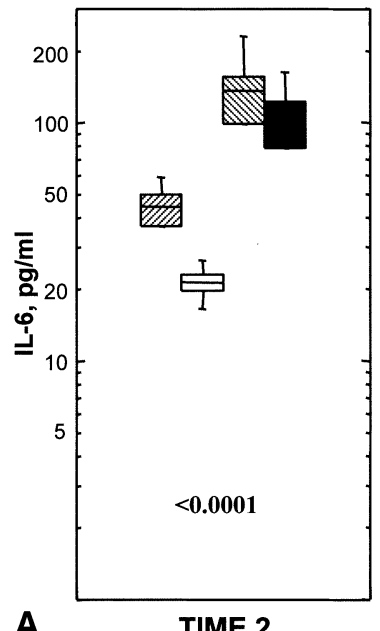

A

TIME 2

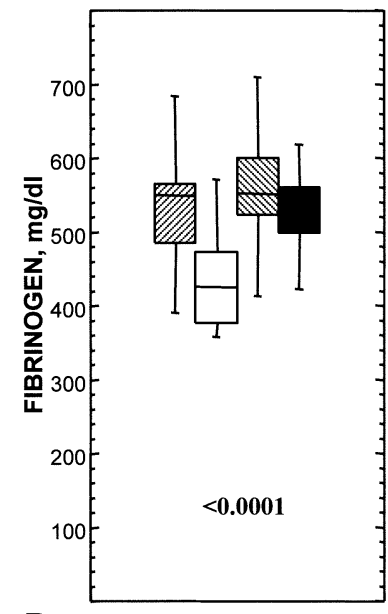

TIME 3

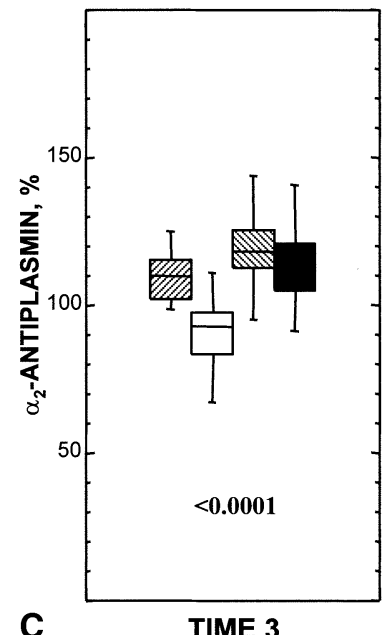

TIME 3

Figure 2. IL-6 levels (A) at time 2 (after arrival in ICU, unadjusted for hemodilution) and fibrinogen levels (B) and $\alpha_{\mathbf{2}}$-antiplasmin levels (C) at time 3 (24 hours after end of operation) in patients undergoing OPCAB or ONCAB and receiving placebo or TA. Box plots with medians (horizontal lines), interquartile ranges (boxes), and 95\% confidence intervals (vertical lines) are shown. Diagonal fills slanting downward from right represent OPCAB and placebo; white fills represent OPCAB and TA; diagonal fills slanting downward from right represent ONCAB and placebo; black fills represent ONCABG and TA. $P$ values refer to analysis of variance for repeated measures (see text for explanation). 
undergoing $\mathrm{OPCAB}$, showing reduction in postoperative bleeding and in the requirement for allogeneic transfusions. ${ }^{18}$ This is the first double-blind study to compare the effects of TA treatment on clinical and laboratory variables in patients undergoing OPCAB and ONCAB. Our pharmacologic protocols for TA reduced by $30 \%$ to $50 \%$ early and 24-hour postoperative blood losses both in patients undergoing OPCAB and in those undergoing ONCAB. Accordingly, the probability of bleeding exceeding $600 \mathrm{~mL}$ in the first postoperative day was reduced $80 \%$ by TA. Because of the insufficient sample size, we could not show a significant reduction in the requirement for allogeneic transfusions, which were, however, between $40 \%$ and $80 \%$ lower in patients treated with TA, irrespective of the type of surgery. Reduced bleeding was not counterbalanced by an increased rate of postoperative thrombotic complications, although our study was not powered adequately to examine this issue.

We have previously shown that both OPCAB and ON$\mathrm{CAB}$ are associated with a net consumption of antithrombin III and fibrinogen, whereas transient decrease in platelet count, greater plasminogen activation, and increased Ddimer formation are only observed with ONCAB. ${ }^{19}$ TA binds to the high-affinity lysine-binding sites of plasminogen and plasmin, preventing binding to fibrin and the resulting fibrin proteolysis. ${ }^{22}$ At least in vitro, however, plasminogen activation is paradoxically accelerated, because TA binding alters the conformation of plasminogen so that it becomes more susceptible to proteolytic activation by activators. ${ }^{23}$ The ex vivo data reported in this article are consistent with these findings. Whereas the changes in fibrinogen, antithrombin III, and platelet counts were not affected, TA prevented postoperative increase in D-dimer levels both in patients undergoing ONCAB and in those undergoing OPCAB to a substantial extent. After correction for hemodilution, however, plasminogen and $\alpha_{2}$-antiplasmin levels were lower after the operation in patients receiving TA, suggesting increased in vivo plasminogen activation to plasmin, complex formation with $\alpha_{2}$-antiplasmin, and clearance. In vivo inhibition of fibrinolysis by TA has been previously reported. ${ }^{24,25}$ With dosages of TA lower than those administered to our patients, Horrow and associates $^{24}$ observed a significant reduction in plasminogen levels, whereas Blauhut and coworkers ${ }^{25}$ observed reduced $\alpha_{2}$-antiplasmin but not plasminogen levels in cardiac surgical patients.

In a study of patients undergoing $\mathrm{ONCAB}$, aprotinin but not $\epsilon$-aminocaproic acid reduced IL-10 and IL-6 levels relative to placebo. ${ }^{26} \mathrm{We}$ show for the first time an antiinflammatory effect of TA treatment in patients undergoing CABG. As expected, CPB induced a greater response in IL-6 levels than that observed in patients undergoing OPCAB; however, postoperative increase in IL-6 was lower in patients treated with TA. TA may modulate the inflamma- tory response related to tissue damage and to the activation of the coagulation system to a greater extent in the presence of "low-grade" inflammation, such as occurs after OPCAB, than in the ONCAB setting. Because of the positive feedback between inflammation and coagulation, control of inflammation may reduce postoperative hypercoagulability and potentially affect the rate of thrombotic complications. Twenty-four hours after the operation, fibrinogen and $\alpha_{2}$ antiplasmin - two acute-phase reactants-were lower in our patients treated with TA and correlated with postoperative IL-6 levels.

In conclusion, this study indicates that TA is effective in reducing bleeding through the prevention of secondary fibrinolysis both in patients undergoing ONCAB and in those undergoing OPCAB. Further randomized studies, enrolling larger numbers of patients, are needed to confirm the antiinflammatory effects of TA and to rule out the potential risk of thrombotic complications.

\section{References}

1. Woodman RC, Harker LA. Bleeding complications associated with cardiopulmonary bypass. Blood. 1990;76:1680-97.

2. Rinder CS, Bohnert J, Rinder HM, Mitchell J, Ault K, Hillmann R. Platelet activation and aggregation during cardiopulmonary bypass. Anesthesiology. 1991;75:388-93.

3. Holloway DS, Summariva L, Sandersara J, Vagher JP, Alexander JC, Caprini JA. Decreased platelet number and function and increased fibrinolysis contribute to postoperative bleeding in cardiopulmonary bypass patients. Thromb Haemost. 1988;59:62-7.

4. Kojima T, Gando S, Kemmotsu O, Mashio H, Goda Y, Kawahigashi $\mathrm{H}$, et al. Another point of view on the mechanism of thrombin generation during cardiopulmonary bypass: role of tissue factor pathway inhibitor. J Cardiothorac Vasc Anesth. 2001;15:60-4.

5. Laffey JG, Boylan JF, Cheng DC. The systemic inflammatory response to cardiac surgery. Anesthesiology. 2002;97:215-52.

6. Asimakopoulos G, Smith PL, Ratnatunga CP, Taylor KM. Lung injury and acute respiratory distress syndrome after cardiopulmonary bypass. Ann Thorac Surg. 1999;68:1107-15.

7. Yacoub M. Off-pump coronary bypass surgery. In search of an identity. Circulation. 2001;104:1743-5.

8. Cartier R, Brann S, Dagenais F, Martineau R, Couturier A. Systematic off-pump coronary artery revascularization in multivessel disease: experience of three hundred cases. J Thorac Cardiovasc Surg. 2000; 119:221-9.

9. Varghese D, Yacoub MH, Trimlett R, Amrani M. Outcome of nonelective coronary artery bypass grafting without cardio-pulmonary bypass. Eur J Cardiothorac Surg. 2001;19:245-8.

10. Nader ND, Khadra WZ, Reich NT, Bacon DR, Salerno TA, Panos AL. Blood product use in cardiac revascularization: comparison of on- and off-pump techniques. Ann Thorac Surg. 1999;68:1640-3.

11. Ascione R, Williams S, Lloyd CT, Sundaramoorthi T, Pitsis AA, Angelini GD. Reduced postoperative blood loss and transfusion requirement after beating-heart coronary operations: a prospective randomized study. J Thorac Cardiovasc Surg. 2001;121:689-96.

12. van Dijk D, Nierich AP, Jansen EW, Nathoe HM, Suyker JL, Diephius JC, et al. Early outcome after off-pump versus on-pump coronary bypass surgery. Results from a randomized study. Circulation. 2001; 104:1761-6.

13. Levi M, Cromheecke ME, de Jonge E, Prins MH, de Mol BJ, Briet E, et al. Pharmacological strategies to decrease excessive blood loss in cardiac surgery: a meta-analysis of clinically relevant endpoints. Lancet. 1999;354:1940-7.

14. Casati V, Guzzon D, Oppizzi M, Cossolini M, Torri G, Calori G, et al. 
Hemostatic effects of aprotinin, tranexamic acid and $\epsilon$-aminocaproic acid in primary cardiac surgery. Ann Thorac Surg. 1999;68:2252-7.

15. Casati V, Guzzon D, Oppizzi M, Bellotti F, Franco A, Gerli C, et al. Tranexamic acid compared with high-dose aprotinin in primary elective heart operations: effects on perioperative bleeding and allogeneic transfusions. J Thorac Cardiovasc Surg. 2000;120:520-7.

16. Casati V, Bellotti F, Gerli C, Franco A, Oppizzi M, Cossolini M, et al. Tranexamic acid administration after cardiac surgery. A prospective, randomized, double-blind, placebo controlled study. Anesthesiology. 2001;94:8-14.

17. Casati V, Sandrelli L, Speziali G, Calori G, Grasso MA, Spagnolo S Hemostatic effects of tranexamic acid in elective thoracic aortic surgery: a prospective, randomized, double-blind, placebo-controlled study. J Thorac Cardiovasc Surg. 2002;123:1084-91.

18. Casati V, Gerli C, Franco A, Torri G, D'Angelo A, Benussi S, et al. Tranexamic acid in off-pump coronary surgery: a preliminary, randomized, double-blind, placebo-controlled study. Ann Thorac Surg. 2001;72:470-5.

19. Casati V, Gerli C, Franco A, Della Valle P, Benussi S, Alfieri O, et al. Activation of coagulation and fibrinolysis during coronary surgery. On-pump versus off-pump techniques. Anesthesiology. 2001;95: 1103-9.

20. Higgins TL, Estafanous FG, Loop FD, Beck GJ, Blum JM, Paranandi $\mathrm{L}$, et al. Stratification of morbidity and mortality outcome by preop- erative risk factors in coronary artery bypass patients. A clinical severity score. JAMA. 1992;267:2344-8.

21. Burman JF, Chung HI, Lane DA, Philippou H, Adami A, Lincoln JC. Role of factor XII in thrombin generation and fibrinolysis during cardiopulmonary bypass. Lancet. 1994;344:1192-3.

22. Verstraete M. Clinical application of inhibitors of fibrinolysis. Drugs. 1985;29:236-61.

23. Sherry S, Marder VJ. Therapy with antifibrinolytic agents. In: Colman RW, Hirsh J, Marder VJ, Salzamn EW, editors. Hemostasis and thrombosis, basic principles and clinical practice. Philadelphia: JB Lippincott; 1994. p. 335-52.

24. Horrow JC, Hlavacek J, Strong MD, Collier W, Brodsky I, Goldman SM, et al. Prophylactic tranexamic acid decreases bleeding after cardiac operations. J Thorac Cardiovasc Surg. 1990;99:70-4.

25. Blauhut B, Harringer W, Bettelheim P, Doran JE, Spath P, Lundsgarard-Hansen P. Comparison of the effects of aprotinin and tranexamic acid on blood loss and related variables after cardiopulmonary bypass. J Thorac Cardiovasc Surg. 1994;108:1083-91.

26. Greilich PE, Okada K, Latham P, Kumar RR, Jessen ME. Aprotinin but not $\epsilon$-aminocaproic acid decreases interleukin-10 after cardiac surgery with extracorporeal circulation: randomized, double-blind, placebo-controlled study in patients receiving aprotinin and $\epsilon$-aminocaproic acid. Circulation. 2001;104(Suppl 1):I265-9.

\section{Bound volumes available to subscribers}

Bound volumes of The Journal of Thoracic and Cardiovascular Surgery are available to subscribers (only) for the 2004 issues from the Publisher, at a cost of $\$ 134.00$ for domestic, $\$ 165.85$ for Canadian, and $\$ 155.00$ for international subscribers for Vol 127 (January-June) and Vol 128 (July-December). Shipping charges are included. Each bound volume contains a subject and author index and all advertising is removed. The binding is durable buckram with the Journal name, volume number, and year stamped in gold on the spine. Payment must accompany all orders. Contact Elsevier Inc., Subscription Customer Service, 6277 Sea Harbor Dr, Orlando, FL 32887, USA; phone 800-654-2452 or 407-345-4000.

Subscriptions must be in force to qualify. Bound volumes are not available in place of a regular Journal subscription. 